\title{
MODA E SUSTENTABILIDADE: CENÁRIOS A PARTIR DO DESIGN ESTRATÉGICO
}

\author{
Giulia Pinheiro Bolzan de Morais \\ UNISINOS \\ giubolzan@gmail.com \\ Dr. Fábio Pezzi Parode \\ UNISINOS \\ fparode@unisinos.br
}

Resumo: Este artigo decorre de uma pesquisa mais ampla em nível de mestrado e tem como objetivo o desenvolvimento de cenários para a prática de moda sustentável, partindo da metodologia do design estratégico. Busca no seu horizonte teórico aproximações com o pensamento complexo e com uma perspectiva crítica do design onde aparece como tópico a relação entre moda e sustentabilidade. Este problema de forma empírico dedutiva é aqui enfrentado através da análise da marca Insecta Shoes. Trata-se de um estudo de caso com viés qualitativo que busca identificar os processos de construção de valor de empresas através do mote sustentabilidade e assim gerar insumos para a construção de cenários para esse campo de atuação.

Palavras-chave: Design Estratégico, Moda, Sustentabilidade, Insecta Shoes. 


\section{INTRODUÇÃO}

Embora esteja em foco atualmente, a relação moda e sustentabilidade ainda é bastante questionada e tênue. Neste contexto, a moda assume um papel de destaque. $\mathrm{Na}$ lógica do sistema de moda, os produtos tradicionalmente têm uma vida útil bastante limitada, por se tratar de um sistema que preza principalmente o presente e a efemeridade, o "estar na moda" ou não (LIPOVESTSKY, 1989). De fato a obsolescência programada é bastante marcante no campo da moda. Atualmente a indústria têxtil é uma das maiores poluidoras do mundo, em razão do grande número de processos químicos envolvidos, bem como do enorme desperdício de água que ocorre no curso da cadeia produtiva (GREENPEACE, 2011).

Para desenvolver este estudo buscamos primeiramente compreender como o design estratégico atua e como pode auxiliar no desenvolvimento de marcas e produtos com qualidades sustentáveis. Também buscamos uma maior compreensão do que é sustentabilidade e como se dá a sua relação com a moda, através de um levantamento bibliográfico. Buscamos ainda com este estudo uma aproximação com o Pensamento Complexo, especialmente no que diz respeito a perspectiva capaz de reunir saberes. Utilizamos a marca Insecta Shoes como referência de empresa posicionada pelo design e que tem como diferencial a proposta de sustentabilidade. Busca-se compreender como a sustentabilidade se materializa nos seus produtos e comunicação. Por fim, busca-se desenvolver novos cenários de atuação para práticas de moda sustentável, através da metodologia do design estratégico.

\section{DESIGN ESTRATÉGICO}

O design estratégico busca a inovação, a criação de novos significados para produtos existentes, e a obtenção de uma vantagem competitiva por consequência. As inovações orientadas pelo design não vem do mercado, e sim constroem novos mercados, e novos nichos. Em um primeiro momento elas podem ter maior dificuldade de aceitação por parte dos consumidores por ser uma novidade, porém após este primeiro período elas tendem a tornar-se grandes forças da empresa, criando produtos com ciclo de vida mais longos, margens de lucro significativas (e sustentáveis) e marcas mais fortes (VERGANTI, 2012).

Uma das principais características do design estratégico é o sistema-produto. Este sistema busca criar uma cadeia de valor que compreende todos os momentos do processo de design, da idealização à distribuição, até que seja absorvida pelo usuário final - figura central de todo este processo (DELANHESI, 2009).

Outro aspecto essencial do design estratégico é a existência do metaprojeto, onde é feita uma pesquisa conceitual mais ampla que serve de inspiração para as escolhas que acontecerão posteriormente. Esta é a principal fase para a inovação já que gera insights criativos para o projeto. É também nesta fase que acontecem a pesquisa blue sky, a análise de tendências, de metatendências e a construção de cenários (DELANHESI, 2009).

Dessa forma, o metaprojeto é tanto uma forma de reunir e analisar dados referentes ao contexto em que o projeto está inserido, quanto uma forma de "expandir os horizontes", trazendo novos insights e possibilidades de inovação (CELASCHI E DESERTI, 2007, p. 57). Ele também auxilia a previsão comportamentos e necessidades futuras, sendo uma ferramenta de grande importância na busca de novas 
oportunidades de serviços e produtos. Várias ferramentas são utilizadas durante um processo projetual de design estratégico, entre elas: Brainstorm, Moodboard, Pesquisa Blue Sky, Cenários e Concept. No que diz respeito ao estudo proposto, cabe-nos definir particularmente Cenários, que segundo Moraes é uma ferramenta utilizada para tentar prever o futuro e guiá-lo, é uma antecipação do futuro que serve de apoio à atividade de design (DE MORAES, 2010). Os cenários servem para auxiliar o projetista e os responsáveis pela direção da organização a mitigar a incerteza, minimizando os impactos dos aleatórios que possam vir a atingir o projeto original de desenvolvimento e preservação desta organização.

\section{DESIGN E MODA}

A moda é um fenômeno bastante complexo e ambíguo. Desde a própria definição de Moda, já encontramos algumas dificuldades pois ela pode ser entendida de duas formas. A primeira, dá conta da moda como indústria que envolve diversas categorias de profissionais, e também a moda como consumo das pessoas e grupos para definir identidades, este entendimento se aproxima bastante da perspectiva de moda como adorno. A segunda definição ressalta a "mudança social específica", que se manifesta além da roupa também em outros aspectos da vida social, é uma mudança que se dá em intervalos constantes, e não é cumulativa pois não acrescenta, apenas substitui as mudanças anteriores (GODART, 2010, pp. 10-11), este entendimento percebe a moda como comportamento.

Em verdade as duas definições são complementares à medida que "a moda, como indústria, produz estilos que são caracterizados por mudanças regulares e não cumulativas". Ela é ao mesmo tempo uma atividade econômica e artística, já que desenvolve produtos e também símbolos, criando objetos portadores de significados (GODART, 2010, p. 12-14).

Porém podemos considerar a ambiguidade da moda principalmente em função de sua dimensão comercial e mercadológica, diga-se sua perspectiva capitalista e empreendedora quando esta não mais respeita os limites do comportamento ético em relação ao avanço da sociedade e da cultura e principalmente com relação a capacidade de resiliência do planeta, estimulando o consumo e as práticas do uso efêmero.

A moda é ainda um fenômeno Complexo pelas inúmeras implicações com outros campos de práticas e saberes, tais como o social, o cultural e até mesmo o político. Envolve questões de ética, responsabilidade e especialmente de projeto de futuro. É exatamente aqui que entra seu potencial inovador e capaz de gerar novos significados. Através da moda é possível de se construir novas percepções e sentidos para o mundo, tal qual uma obra de arte o faz através de suas prerrogativas. Tal como uma obra de arte é uma peça de cultura, um acessório ou uma peça de vestuário, enquanto criação humana também é capaz de gerar efeitos de sentido afetando a sensibilidade e provocando transformações nas subjetividades. Por isso, a moda não pode ser vista de forma simplificada, separada de outros sistemas. Como dizem Morin e Le Moigne o pensamento complexo é capaz de reunir (complexus: aquilo que é tecido conjuntamente), de contextualizar, de globalizar, mas, ao mesmo tempo, capaz de reconhecer o singular, o individual, o concreto (MORIN e LE MOIGNE, 2000, p. 206).

Portanto, considerando as reflexões feitas anteriormente acerca do papel do design, o designer de moda tem a tarefa de projetar novos significados socialmente 
instituídos e novos benefícios nos produtos de moda. Sendo assim, o design de moda tem um papel especialmente relevante, já que o designer tem na moda um instrumento com potencial para inspirar/incentivar novas ideias e comportamentos.

\section{SUSTENTABILIDADE}

Hoje, o planeta passa por um esgotamento dos seus recursos naturais que vem acompanhado de mudanças climáticas e que afetam a configuração e a segurança dos territórios globais habitados. A recente assinatura do Acordo sobre as transformações climáticas firmado em Paris em 2015 (COP-21, 2015), por mais de 150 países define as metas para a ação dos países signatários em relação a limitação do aumento da temperatura da Terra que deverá ser inferior aos $2^{\circ} \mathrm{C}$. Além do desgaste ambiental propriamente dito, este comportamento destrutivo tem consequências indiretas também, como a saturação do mercado, o desemprego, o aumento das guerras regionais pelo controle de recursos naturais, entre outros. Isto coloca a "questão ambiental" no centro de uma série de problemas que devem ser tratados conjuntamente, partindo de questões sociais e econômicas (MANZINI, 2008).

Ainda conforme Manzini, a economia está passando por um processo de transição, e caminhando para o que ele chama de "a próxima economia" (MANZINI apud DE MORAES, 2010, p. IX). Esta próxima economia não será mais baseada em bens de consumo ou produtos, ela será "orientada pelo serviço: uma economia baseada em redes sociais e tecnológicas, em que pessoas, produtos e lugares interagem para obter um valor de reconhecimento comum". Ela também depende da convergência de quatro domínios econômicos: o mercado, o estado, as verbas públicas e os negócios domésticos. Por fim, ela será completamente ligada à inovação social, se tornando, desta forma, muito mais atrelada aos usuários do que à especialistas ou políticos (MANZINI apud DE MORAES, 2010).

Para ser considerado sustentável, um produto deve ser ambientalmente correto e socialmente justo. Além destes dois pilares, a sustentabilidade "completa" para ser assim entendida, ainda tem um terceiro requisito que é a viabilidade econômica (GWILT, 2011, apud ANICET; RÜTHSCHILLING, 2013).

Neste cenário, o papel do designer seria o de oferecer soluções inovadoras aos problemas enfrentados. Particularmente, o design estratégico tem condições de produzir cenários e visões compartilhadas sobre futuros possíveis e sustentáveis. No mesmo sentido, as empresas devem dar uma orientação estratégica às suas atividades, combinando as suas próprias necessidades com estes novos critérios de sustentabilidade (MANZINI, 2008).

No caso da moda nota-se que o caminho para a construção de práticas mais efetivas dentro do escopo da sustentabilidade depende de vários fatores, desde o designer enquanto ator social, passando pela produção responsável até o consumidor final em sua relação com os artefatos produzidos.

A seguir partiremos para a análise de nosso objeto de estudo, o caso Insecta Shoes, uma marca de sapatos reconhecida pelo público como alternativa e engajada no que diz respeito a sustentabilidade. Seria preciso ainda ressaltar uma corrente dentro do design estratégico, aquela que busca a inovação social e cultural, cuja premissa repousa na perspectiva já apontada por Manzini (2008), que é a estimulação da ecologia do tempo, do tempo lento e contemplativo. 


\section{PROCEDIMENTOS METODOLÓGICOS}

O metaprojeto auxilia na geração de conceitos, ele não pretende dar respostas simples para um problema, e sim sugerir referências que possam orientar o projeto e a definição de estratégias. Em se tratando de questões relacionadas à sustentabilidade, este é um momento de reflexão crítica que pode questionar desde o conceito de sustentabilidade e seus requisitos.

Utilizando a marca Insecta Shoes como referência, selecionamos algumas ferramentas de metaprojeto, quais sejam o brainstorm, mapa de polaridades e cenários com o objetivo de gerar insights e sugerir possibilidades de ação para empresas que buscam adotar um posicionamento voltado para a sustentabilidade.

Partimos de uma pesquisa contextual para compreender melhor a forma de atuação e posicionamento da Insecta Shoes. Em seguida, conduzimos um brainstorm com três designers e partindo da ideia de sustentabilidade, por ser o foco do presente trabalho e um dos diferenciais competitivos da marca. Com base no resultado do brainstorm selecionamos as ideias de slow e local para direcionar o mapa de polaridades, fazendo o cruzamento com os opostos fast e global, que representam alguns desafios principalmente quando pensamos em uma expansão e atuação em maior escala de marcas de moda voltadas à sustentabilidade. Por fim, o mapa de polaridades orientou a criação de quatro cenários possíveis, que ainda sugerem algumas ideias iniciais que podem ser desenvolvidas mais profundamente em novos estudos.

\section{RESULTADOS}

\subsection{Pesquisa Contextual}

A Insecta Shoes é uma empresa criada em 2014 que tem por objetivo "trazer para o mundo um pouco mais de cor e consciência" através de sapatos "veganos, colecionáveis e mutantes" (INSECTA SHOES, 2016), confeccionados a partir de peças vintage transformadas.

\footnotetext{
"Nossa palavra-chave é reaproveitamento: aumentar a vida útil do que já existe pelo mundo, sempre de modo criativo e descontraído. Garimpamos peças de roupas usadas e, através de um processo artesanal, as transformamos em sapatos $100 \%$ exclusivos. Os mais diversos tecidos e estampas daqueles modelitos abandonados viram botas e oxfords veganos, sem nenhum uso de matéria-prima de origem animal. Produzidos no Brasil para o mundo, todo Insecta é único, o que significa que nenhum modelo se repete, nunca!" (INSECTA SHOES, 2016)
}

A marca trabalha com um processo de upcycling

que significa utilizar um material já utilizado ou o resíduo de um produto tal como foi encontrado, sem despender mais energia na reutilização do mesmo, ou seja, sem reciclar o produto. É um processo de recuperação que transforma os resíduos desperdiçados em novos produtos ou materiais com superior qualidade e valor ambiental (ANICET et al., 2011, p. 3). 


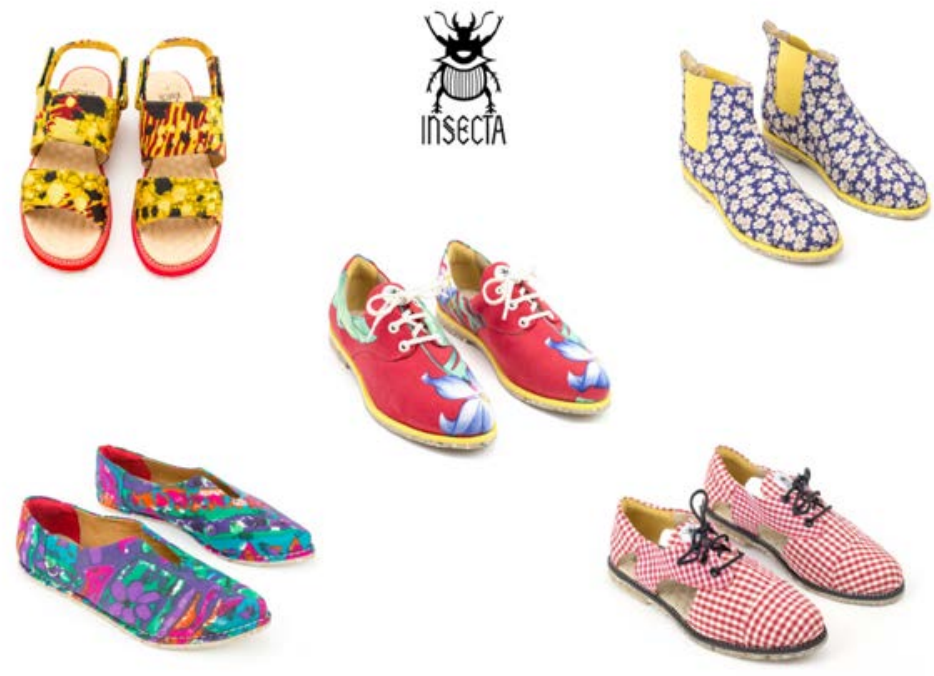

Figura 1 - Produtos Insecta Shoes

Fonte: Adaptado pelos autores de www.insectashoes.com.br <Acesso em 30 de junho de 2016>
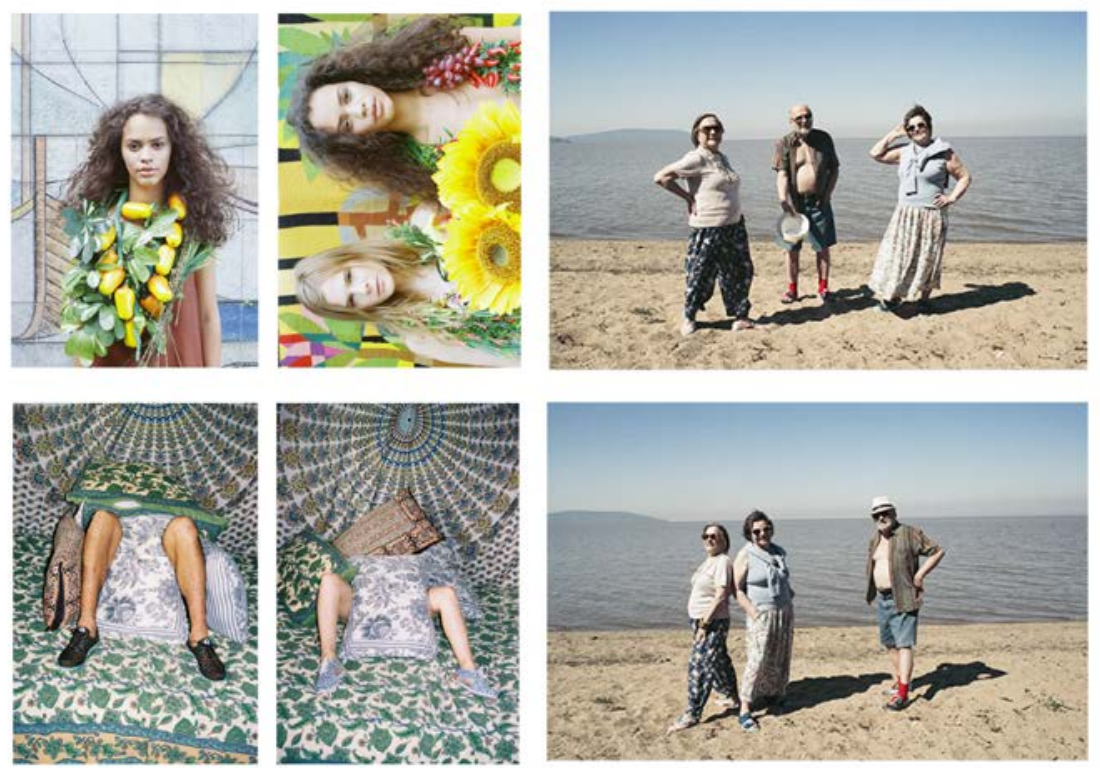

Figura 2 - Moodboard Insecta Shoes

Fonte: Adaptado pelos autores de www.insectashoes.com.br <Acesso em 30 de junho de 2016>

Pode se perceber na figura 2 e pela linguagem utilizada pela marca a sua irreverência e que ela não se atém a padrões. Os sapatos produzidos são unissex, se desvinculando de qualquer ideia de gênero, ou de produtos "apropriados" para homens e mulheres, também são usados modelos idosos em suas campanhas, para afastar preconceitos de idade. A marca ainda produz editoriais próprios, conceituais, reforçando a visão que tem sobre seus produtos e o estilo de vida que quer passar. Também são feitos eventos e campanhas para incentivar o consumo consciente e o slow fashion ${ }^{1}$, como feiras de troca e brechós.

\footnotetext{
${ }^{1} \mathrm{O}$ movimento slow fashion surgiu como um sistema de produção de moda alternativo ao fast fashion. Ele engloba um pensamento sustentável, no sentido de "um novo conjunto de atitudes e valores que possam minimizar os impactos na sociedade, tanto no que diz respeito a questões ambientais como também sociais e econômicas"
} 
No blog da marca encontramos desde receitas veganas, dicas de viagem, até achados de artistas locais, meio ambiente e dicas de bem estar. Todos estes aspectos reforçam a imagem da marca e dão suporte e ainda mais credibilidade para o discurso de sustentabilidade dos produtos.

\subsection{Brainstorm}

Considerando a filosofia da marca, realizamos um brainstorm partindo da palavra sustentabilidade.

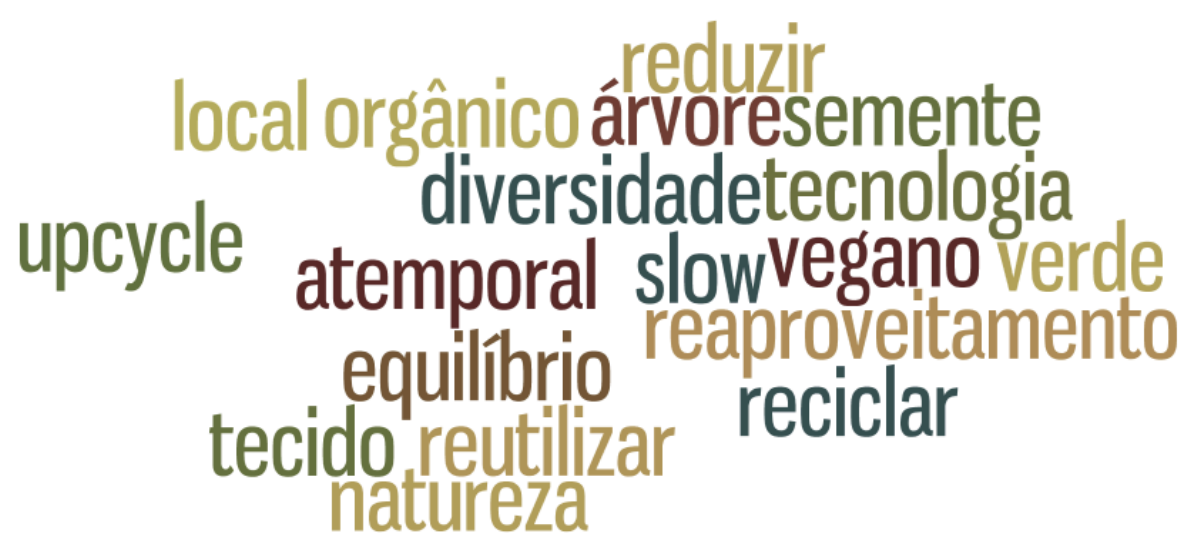

Figura 3 - Brainstorm

Fonte: Elaborado pelos autores, com base na pesquisa realizada

A partir do resultado, selecionamos as palavras slow e local para orientar o mapa de polaridades e os cenários.

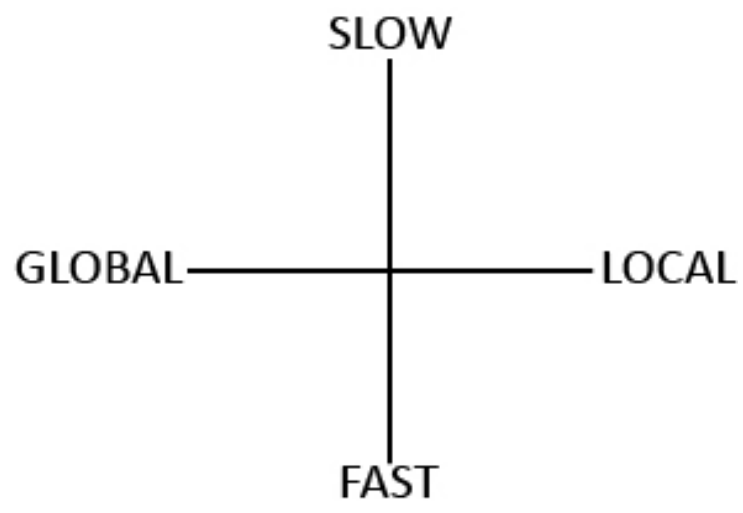

Figura 3 - Mapa de Polaridades

Fonte: Elaborado pelos autores, com base na pesquisa realizada

(MORELLI, 2010, p. 2). Este pensamento engloba desde uma forma de produção que considere os impactos ambientais e sociais, até uma desaceleração do consumo. 


\subsection{Cenários}

A partir dos cruzamentos entre slow, fast, local e global, foram desenvolvidos quatro cenários de atuação para prática de moda sustentável.

\subsubsection{Global x Fast}

Este cenário considerou a expansão da empresa para um modelo de atuação rápida e global. Este é o cenário das empresas que atuam em nível global, em um ritmo rápido de entrega de novidades.

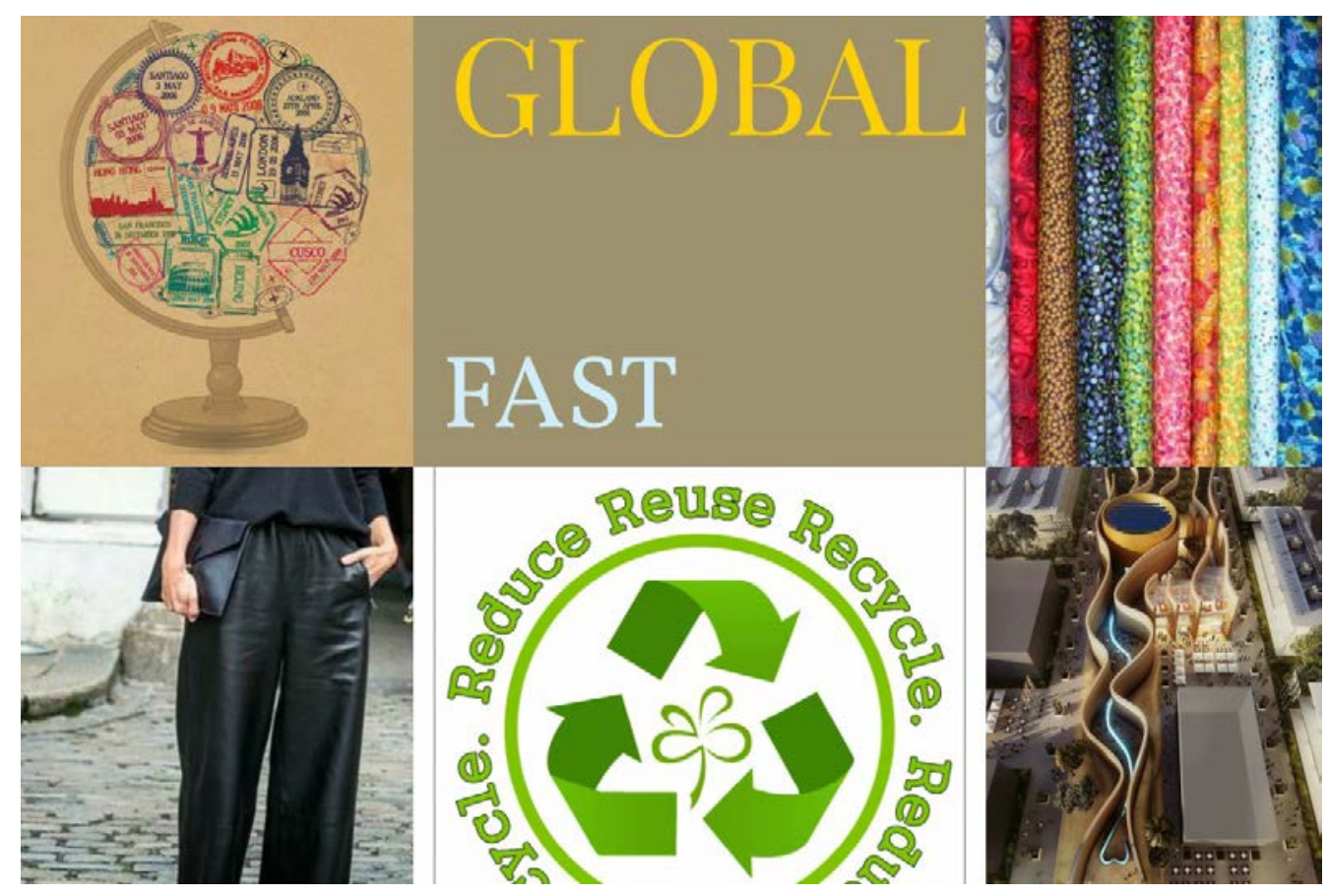

Figura 4 - Cenário Global x Fast

Fonte: Elaborado pelos autores, com base na pesquisa realizada

Neste cenário os aspectos de sustentabilidade do produto e da cadeia de produção tem destaque. Considerando a necessidade de aumento da produção e da eficiência dos processos a empresa teria que rever a matéria prima utilizada, já que o upcycle é um processo bastante artesanal e difícil de ser trabalhado em maior escala. As opções podem envolver o uso de tecidos reciclados ou orgânicos. Com o aumento da escala de produção seria interessante imaginar uma forma de fechar o ciclo do produto, incluindo uma forma de descarte do produto que não impactasse o ambiente.

\subsubsection{Global x Slow}

Este cenário considerou a expansão da empresa para um modelo de atuação lenta e global. 


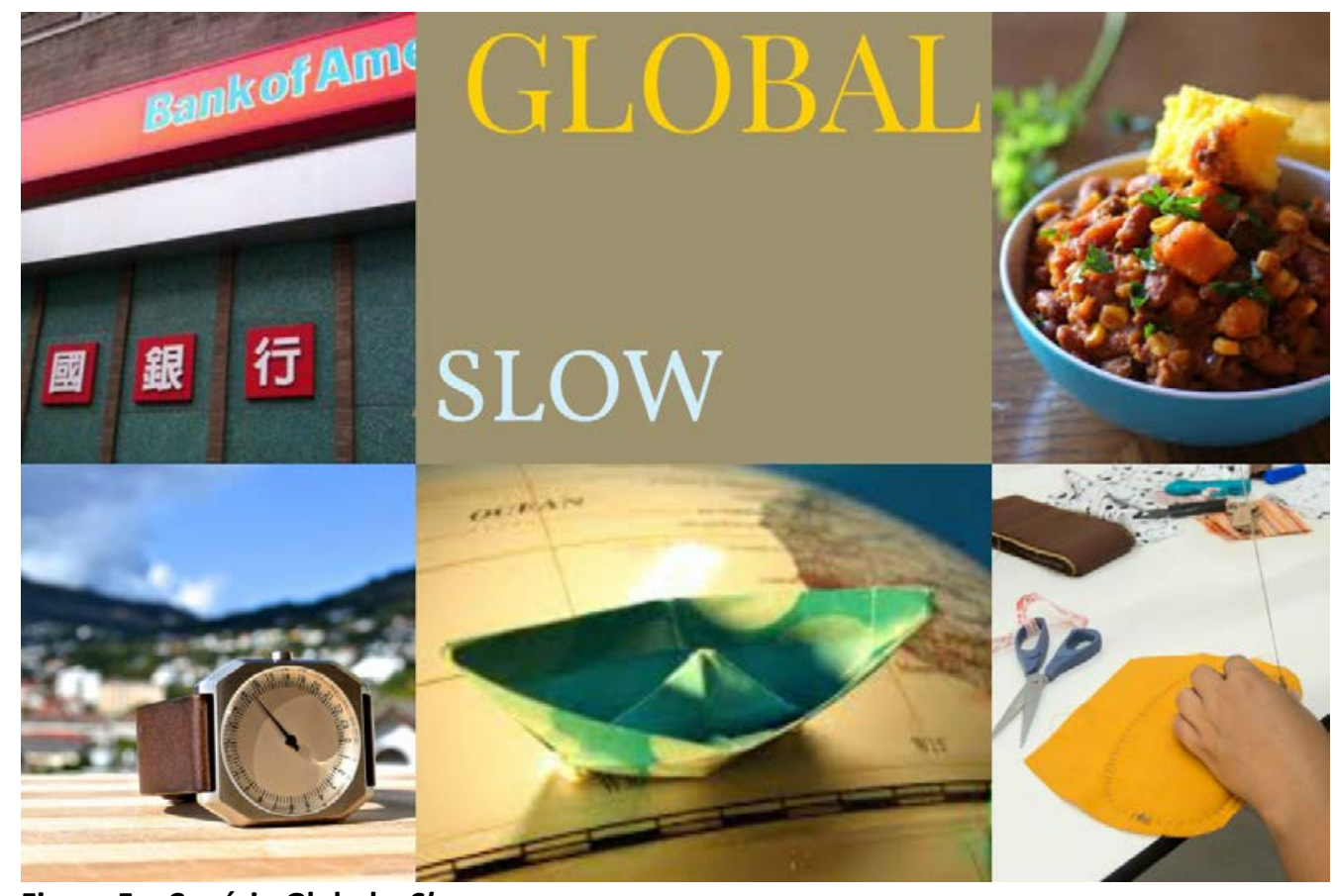

Figura 5 - Cenário Global x Slow

Fonte: Elaborado pelos autores, com base na pesquisa realizada

Uma possibilidade deste cenário é que, mesmo considerando uma expansão internacional, a empresa pode pensar em uma produção local e mais lenta, dentro de uma lógica de atuação "glocal". Distribuindo a produção para os locais onde instalar suas lojas a marca estaria ajudando a gerar renda para a comunidade.

\subsubsection{Local x Fast}

O terceiro cenário considerou a expansão da empresa para um modelo de atuação rápida e local.

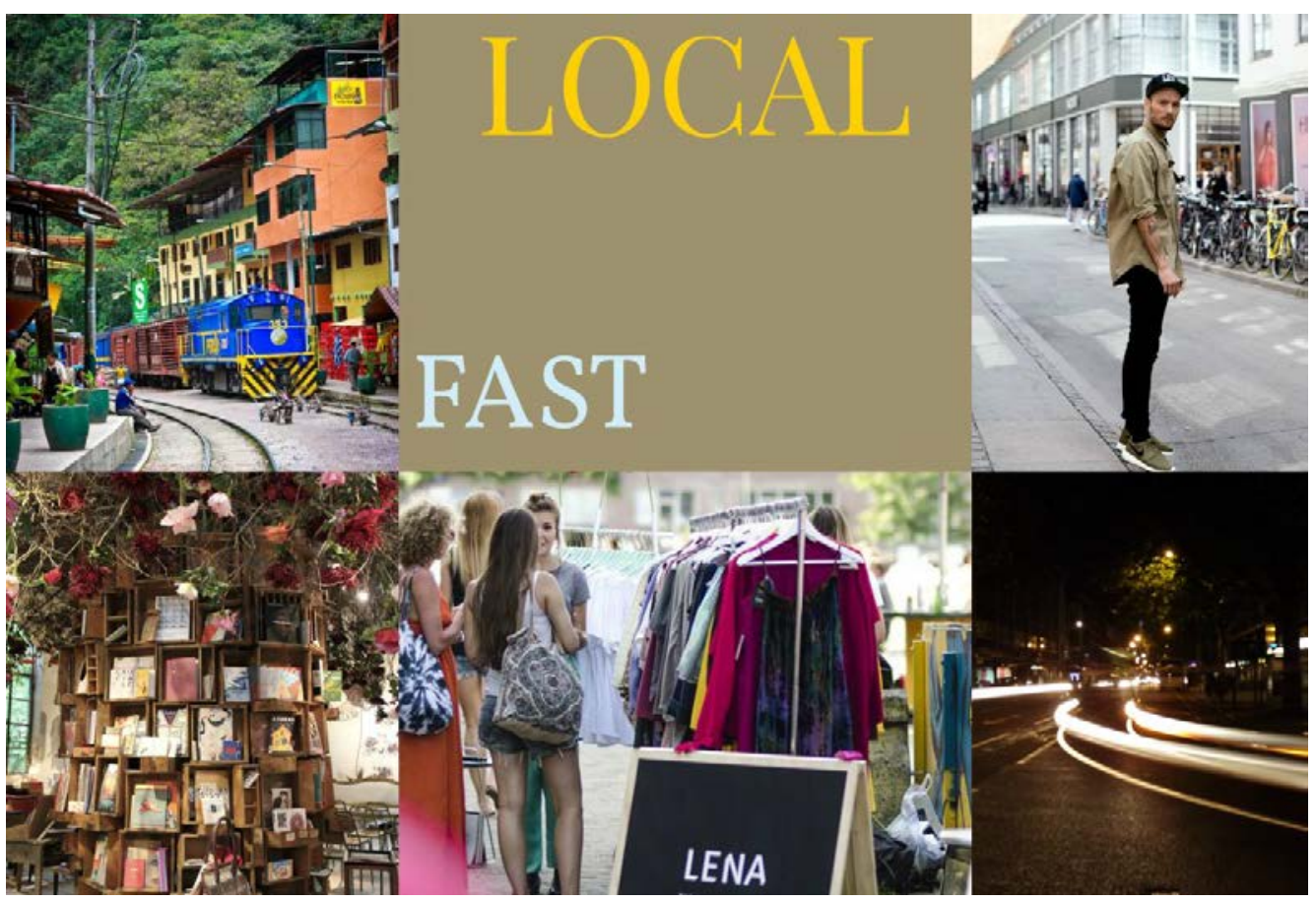

Figura 5 - Cenário Local X Fast

Fonte: Elaborado pelos autores, com base na pesquisa realizada 
Considerando este cenário, podemos pensar a possibilidade da empresa continuar atuando em âmbito local, porém com uma variedade maior de produtos voltados às tendências. A produção acelerada obrigaria a marca a ter mais funcionários a fim de manter o controle da produção e das condições de trabalho, além de diminuir alguns custos. Este parece ser um cenário mais afastado dos ideais da marca, já que envolve um consumo mais acelerado, porém aqui poderiam ser pensados modelos diferentes de negócios que favorecessem o acesso aos produtos ao invés da posse, como as "bibliotecas" de roupas, que permitem uma troca rápida, mas sem o impacto do descarte excessivo.

\subsubsection{Local x Slow}

Este cenário considerou a expansão da empresa para um modelo de atuação lenta e local.

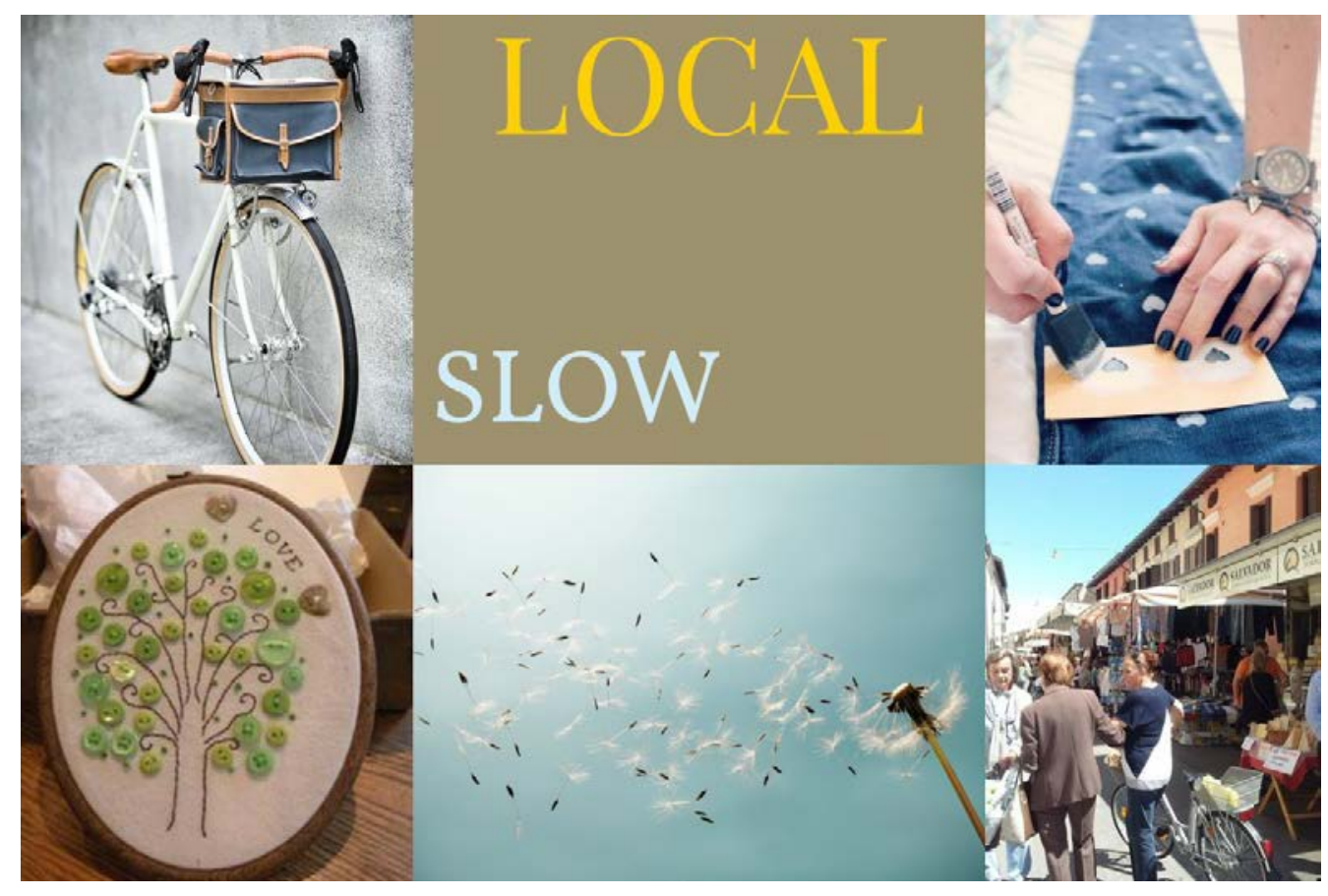

Figura 5 - Cenário Local X Slow

Fonte: Elaborado pelos autores, com base na pesquisa realizada

Este é o cenário mais próximo da situação atual da Insecta Shoes, pois remete a uma produção quase artesanal, em âmbito local, aproximando a fábrica dos clientes e agregando valor ao produto. A empresa poderia também incluir diferentes técnicas como o bordado e a customização para ter produtos ainda mais exclusivos. Neste contexto, seria possível pensar em novos modelos de negócios para a marca além da venda direta ao consumidor, mais voltados à cooperação.

\section{CONSIDERAÇÕES FINAIS}

Neste estudo, desenvolvemos reflexões sobre o papel cultural da moda na transformação da sociedade, buscando questionar o lugar da moda no processo de constituição de uma cultura mais sustentável. Buscamos evidenciar a complexidade da moda enquanto disciplina que encontra-se em amplo crescimento na sua relação com 
outras disciplinas, ou seja, sua dinâmica transdisciplinar lhe garante uma qualificação constante nos processos reflexivos e aplicados, permitindo-Ihe uma atualização com relação aos problemas da sociedade, entre eles, a sustentabilidade.

Ainda, apresentamos a abordagem da moda pelo viés do design estratégico, propondo cenários que possam estimular as práticas projetuais na direção de uma cultura pela sustentabilidade, evidenciando a partir da marca e organização Insecta Shoes, caminhos para que outras empresas com essas mesmas prerrogativas possam ter referências quanto as suas práticas e conceitos sobre mercado e sustentabilidade.

Neste sentido o design estratégico enquanto disciplina e a construção de cenários enquanto ferramenta se mostraram importantes para a geração de insights que possibilitem a inovação e a geração de soluções criativas e sustentáveis.

\section{REFERÊNCIAS}

ANICET, Anne; RÜTHSCHILLING, Evelise Anicet. Relações entre Moda e Sustentabilidade. In: Colóquio de Moda, 9, 2013, Fortaleza. Anais eletrônicos. Disponível em < http://www.coloquiomoda.com.br/anais/. Acesso em 12 de abril de 2016.

ANICET, Anne; BESSA, Pedro; BROEGA, Ana Cristina. Ações na área de moda em busca de um design sustentável. In: Colóquio de Moda, 7, 2011, Maringá. Disponível em < http://www.coloquiomoda.com.br/anais/. Acesso em 12 de abril de 2015.

CELASCHI, Flaviano; DESERTI, Alessandro. Design e Innovazione: strumenti e pratiche per la ricerca applicata. Roma: Carocci Editore, 2007.

COP21 Paris, 2015. Disponível em: < http://unfccc.int/resource/docs/2015/cop21/eng/l09r01.pdf >. Acesso em 13 de abril de 2016

DE MORAES, Dijon. Metaprojeto: o design do design. São Paulo: Blucher, 2010.

DELANHESI. Rogério. Bairro Moinhos de Vento: construindo identidades. Dissertação (Mestrado em Design Estratégico) - Programa de Pós-Graduação em Design, Universidade do Vale do Rio dos Sinos (UNISINOS), Porto Alegre, 2009.

GODART, Frédéric. Sociologia da Moda. Tradução: Lea P. Zylberlicht. São Paulo: Editora Senac, 2010.

GREENPEACE. Detox. Amsterdã: 2011. Disponível em < http://www.greenpeace.org/international/en/campaigns/detox/fashion/about/ >. Acesso em 16 de junho de 2015.

INSECTA SHOES. Sobre a Insecta. Porto Alegre, 2016. Disponível em < http://www.insectashoes.com/ > . Acesso em 30 de abril de 2016.

LIPOVETSKI, Gilles. O Império do Efêmero - a moda e seus destinos na sociedade moderna. São Paulo: Companhia das Letras, 1989.

MANZINI, Ezio. Design para a Inovação Social e Sustentabilidade: comunidades criativas, organizações colaborativas e novas redes projetuais. Tradução: Carla Cipolla. Rio de Janeiro: E-papers, 2008. 
MORELLI, Graziela. Paradoxos da sociedade contemporânea: o movimento slow fashion. In: Colóquio de Moda, 7, 2011. Anais eletrônicos. Disponível em: < http://www.coloquiomoda.com.br/anais/>. Acesso em 10 de maio de 2016.

MORIN, Edgar; LE MOIGNE, Jean-Louis. A Inteligência da Complexidade. São Paulo: Petrópolis, 2000.

VERGANTI, Roberto. Design-Driven Innovation: Como criar produtos com significados que deixarão as pessoas apaixonadas. Info Paper, $4^{a}$ edição. São Paulo: Senai São Paulo Design, 2012. Disponível em < http://www.sp.senai.br/spdesign/ >. Acesso em 27 de abril de 2016. 